\title{
Article \\ Flow of Oil and Water through the Nozzle and Cavitation ${ }^{\dagger}$
}

\author{
Jana Jablonská *, Milada Kozubková and Marian Bojko
}

check for

updates

Citation: Jablonská, J.; Kozubková, M.; Bojko, M. Flow of Oil and Water through the Nozzle and Cavitation. Processes 2021, 9, 1936. https:// doi.org/10.3390/pr9111936

Academic Editor: Sergio Bobbo

Received: 30 August 2021

Accepted: 25 October 2021

Published: 28 October 2021

Publisher's Note: MDPI stays neutral with regard to jurisdictional claims in published maps and institutional affiliations.

Copyright: (c) 2021 by the authors. Licensee MDPI, Basel, Switzerland. This article is an open access article distributed under the terms and conditions of the Creative Commons Attribution (CC BY) license (https:// creativecommons.org/licenses/by/ $4.0 /)$.
Department of Hydromechanics and Hydraulic Equipment, Faculty of Mechanical Engineering, VSB - Technical University of Ostrava, 17. listopadu 2172/15, 70800 Ostrava-Poruba, Czech Republic; milada.kozubkova@vsb.cz (M.K.); marian.bojko@vsb.cz (M.B.)

* Correspondence: jana.jablonska@vsb.cz

+ This paper is an extended version of a paper published in the international conference: "XXII. International Scientific Conference-The Application of Experimental and Numerical Methods in Fluid Mechanics and Energy 2020 (AEaNMiFMaE-2020), Piešt'any, Slovakia, 7-9 October 2020.

\begin{abstract}
Today, the correct understanding of the issue of oil and water cavitation is important due to the growing demands on working conditions in hydraulic systems (pressure and flow rate). This article deals with the measurement and subsequent mathematical modeling of cavitation in a convergent-divergent nozzle of circular cross-section. Cavitation depends on the physical properties of the flowing medium as a function of temperature. Usually, cavitation in water is defined by a two-phase flow of water and vapor, but the air contained in the water significantly affects cavitation. There is usually no vapor cavitation in the oil. Far more often, cavitation in oil is caused by the air it contains. For comparison, cavitation in water and oil was generated in experiments with an identical nozzle. The measurement was used to define boundary conditions in mathematical models and to verify simulations. The problem of cavitation was solved by three variants of multiphase flow, single-phase flow (water, oil), two-phase flow (water-vapor, oil-air) and three-phase flow (water-vapor-air, oil-vapor-air). A turbulent model with cavitation was used for all variants. The verification of simulations shows that for water cavitation it is necessary to use a three-phase model (water, vapor, air) and for oil cavitation a two-phase model (oil, air) is sufficient. The measurement results confirm the importance of the air phase in modeling cavitation in both water and oil.
\end{abstract}

Keywords: oil cavitation; water cavitation; mathematical modeling; CFD; multiphase flow

\section{Introduction}

Liquid at a constant temperature can be exposed to a decreasing pressure, which can reach up to the pressure of saturated vapor. each liquid contains microbubbles of noncondensable (dissolved) gases or nuclei, which can grow and form cavities as the pressure decreases. This process is called cavitation. Cavitation occurs in low-pressure regions and causes a substantial change in density. Due to cavitation shock, the surface of the components (pump blades, valves, etc.) is locally damaged and so-called cavitation erosion occurs. Its consequences can manifest themselves after only a few hours of operation.

Cavitation is supported by large temperature changes and chemical and electrolytic influences. The solubility of oxygen in liquids increases with pressure [1], which affects the higher intensity of chemical corrosion. In the literature [1], it is stated that up to $50^{\circ} \mathrm{C}$, the solubility of oxygen in water decreases as a function of temperature. The intensity of cavitation is supported by impurity particles in the liquid.

Currently, the Venturi tube is widely used to study cavitation. The literature [2] states that cavitation facilitates the synthesis of biofuels, helps to degrade contaminants, and disinfect harmful microorganisms (wastewater remediation), etc. Venturi tubes are widely used to generate microbubbles by hydrodynamic cavitation [3]. In much of the literature $[3,4]$ dealing with the flow in a Venturi tube, water is considered. The authors have already dealt with the flow of oil through constrictions in the literature [5] and now this issue is enriched with modeling. 
Investigation of the development of cavitation in oil flow is described in the literature mainly concerning flow through narrow gaps such as the oil film seal with spiral grooves [6], cavitation in bearings [7] and lubricating film [8]. The literature [7] describes the detection of vapor cavitation in bearings using vibrational and acoustic methods. The dependence of the height of the lubricating film on the formation of cavitation is described in the literature [8]. Oil cavitation, in practice, is important in production and the literature [9] describes the production of biodiesel from used oil using hydrodynamic cavitation, and equipment using hydrodynamic cavitation to produce a highly stable oil-in-water emulsion [10]. However, in conventional hydraulic systems, cavitation can also occur when flowing through a hydraulic element. Therefore, to simplify the problem of oil flow with cavitation, modeling of this flow and comparison of the flow in terms of flowing fluid with the same geometry was also performed.

\section{Physical Properties of Fluids}

As for the flow of liquid through a convergent-divergent nozzle, it is necessary to know the physical properties of the flowing medium. The viscosity of liquid depends mainly on the temperature. In general, with increasing temperature, the change in momentum of particles in the moving layers of liquids is more intense and the viscosity and tangential stress decrease (see Figure 1a). The viscosity of the liquid is also a function of pressure. With increasing pressure, the viscosity increases significantly, but only at higher pressures (up to $100 \mathrm{MPa}$ ) [11,12]. The density of the liquid is also significantly affected by temperature and decreases with increasing temperature (see Figure 1b).

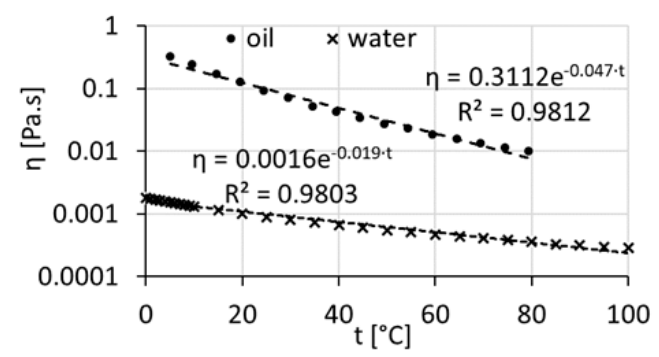

(a)

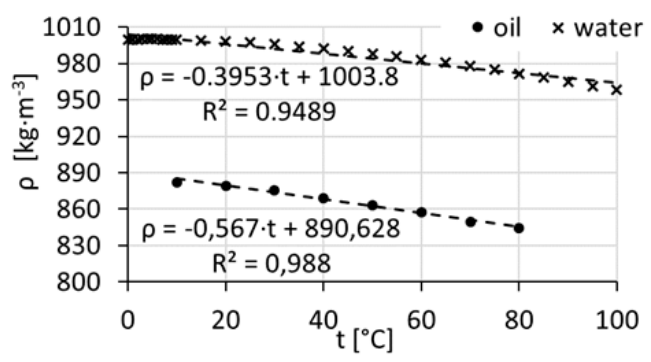

(b)

Figure 1. Physical properties of fluids. (a) Dependence of dynamic viscosity $\eta$ vs. temperature $t$; (b) Dependence of density $\varrho$ vs. temperature $t$.

It is generally assumed that the cavitation pressure $p_{c a v}(\mathrm{~Pa})$ is the same as the saturated vapor pressure of the liquid $p_{\text {vap }}(\mathrm{Pa})$ at a given temperature $p_{\text {cav }}=p_{\text {vap }}$. Saturated vapor pressure is the highest pressure at which a substance exists in an equilibrium gaseous state at a given temperature. It is also the lowest pressure at which a substance can exist in a liquid or solid state at a given temperature. The vapor pressure of substances increases exponentially with temperature. [13] The saturated vapor pressure of oil is very low, in contrast to the water (see Figure $2 a, b)$.

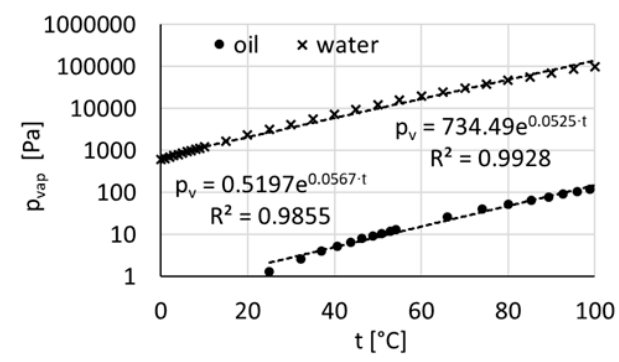

(a)

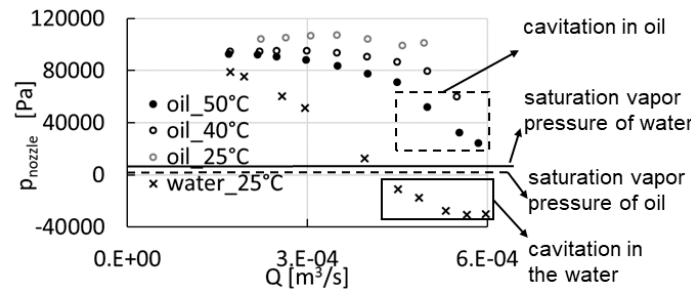

(b)

Figure 2. (a) Dependence of saturation vapor pressure $p_{\text {vap }}(\mathrm{Pa})$ vs. temperature $t\left({ }^{\circ} \mathrm{C}\right)$. (b) Dependence of pressure at the narrowest point $p_{\text {nozzle }}(\mathrm{Pa}) \mathrm{vs}$. volume flow rate $Q\left(\mathrm{~m}^{3} \cdot \mathrm{s}^{-1}\right)$. 
As already mentioned, the presence of air in liquid (water, oil) has adverse effects on the quality of the liquid, especially oil-oxidation, foaming, and reducing the modulus of elasticity. Air supports the formation of cavitation. [11] Dissolved air is excreted from the liquid, the amount of which depends on the properties of the liquid, gas, pressure and temperature. Dissolved air can begin to release and form bubbles, especially in the area where the pressure decreases. The amount of dissolved air can be expressed by the relationship:

$$
V_{p}=V_{k} \alpha_{p} \frac{p}{p_{0}}\left(\mathrm{~m}^{3}\right)
$$

where $V_{p}\left(\mathrm{~m}^{3}\right)$ is the volume of dissolved gas, $V_{k}\left(\mathrm{~m}^{3}\right)$ is the volume of liquid, $\alpha_{p}(1)$ is the coefficient of solubility of a gas in a liquid, $p(\mathrm{~Pa})$ is the absolute pressure at the surface and $p_{0}(\mathrm{~Pa})$ is the atmospheric pressure [11].

The value of the solubility coefficient is given for water [1], mineral oil and other liquids [14]. The publication [15] states that the concentration of non-condensable gas in water at $20{ }^{\circ} \mathrm{C}$ is from $2-3 \%$ and the concentration of invasive oil is up to $8 \%$. All publications [1,11,14-16] agree on the amount of air contained in water and oil.

The concentration of dissolved gas $C_{i}\left(\mathrm{mg} \cdot \mathrm{L}^{-1}\right)$ in water is directly proportional to the partial pressure of the gas $P_{i}(\mathrm{~Pa})$ above its level. This dependence is explained by Henry's law:

$$
C_{i}=K_{i} P_{i}
$$

where the value of $K_{i}$ is the absorption coefficient characterizing the solubility of gas as a function of temperature.

When modeling, the properties of liquid, i.e., density and dynamic viscosity, had to be chosen. For water and oil, the dynamic viscosity and density as a function of temperature were defined using an approximation equation, see Figure 1a. The density for water vapor, oil vapor and air were defined as a function of temperature and pressure using the equation of state. The dynamic viscosity for gases was defined in [17].

\section{Description of Measuring Equipment}

The basic hydraulic parameters were measured on the test circuit. Since the investigated element, the convergent-divergent nozzle, was transparent the emergence and development of cavitation could be observed. The same nozzle was used on the water and oil circuit pipes; the differences were due to technical reasons only in the location of sensors (see Table 1). The liquid was pumped by a pump/hydrogenerator into the circuit where the ball valve and the flowmeter were connected. The liquid then flowed through the transparent nozzle and the ball valve back into the tank.

Table 1. Basic dimensions (mm), see Figure 3.

\begin{tabular}{ccc}
\hline Dimensions & Water & Oil \\
\hline$\varnothing D$ & 20 & 20 \\
$\varnothing d$ & 6 & 6 \\
$a$ & 300 & 110 \\
$b$ & 25 & 25 \\
$c$ & 70 & 70 \\
$d$ & 385 & 195 \\
$(L)$ & 780 & 400 \\
position & horizontal & vertical \\
\hline
\end{tabular}

The tooth flowmeter GFM-70 used had a range from $0.7-70 \mathrm{dm}^{3} \cdot \mathrm{min}^{-1}$ on the oil circuit with an accuracy of $0.5 \%$ and the induction flow meter FLONET FN20XX.1 had a range from $0.72-72 \mathrm{~m}^{3} \cdot \mathrm{s}^{-1}$ on the water circuit with an accuracy of $0.2 \%$. In front of and behind the nozzle we used sensors from the manufacturer Hydrotechnik with ranges from (-1-1) bar and (-1-5) bar, the pressures were measured, written into the evaluation equipment and then copied into the computer (all pressure gauges had an accuracy of $0.5 \%$ ). 
When cavitation occurred, a high-speed camera record was made and sent to a computer. The recording was captured by a high-speed Photron Mini UX50 camera. The frame rate was 8000 frames per second with a resolution of $1280 \times 296$ pixels. A thermometer was placed in the tank. The circuit diagram and nozzle dimensions are shown in Figure 3.
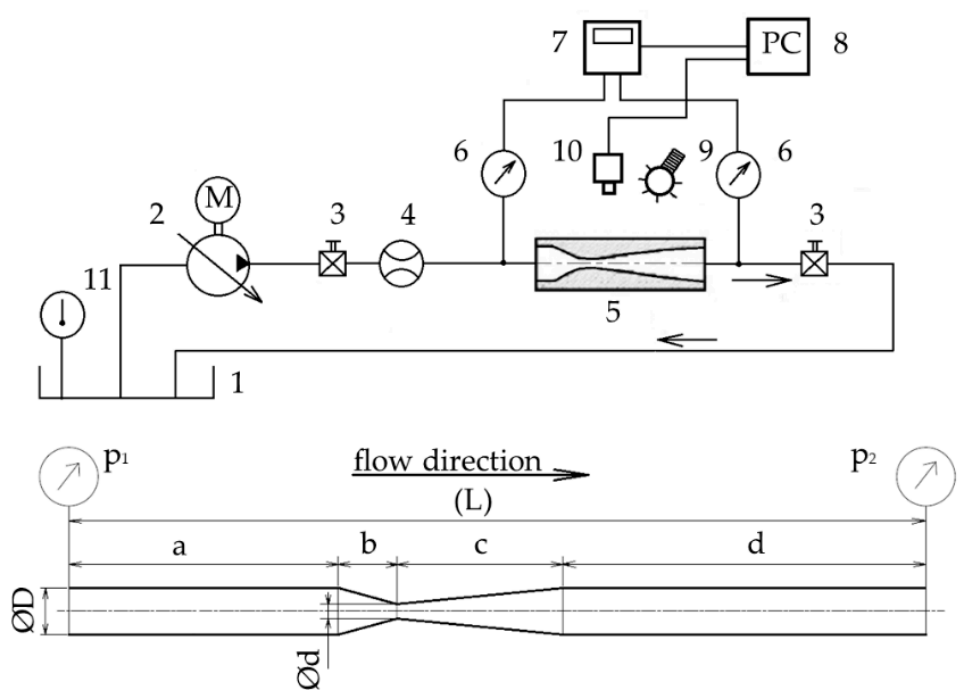

Figure 3. Measuring equipment and basic dimensions (mm): (1) tank; (2) hydro generator/pump; (3) ball valve; (4) flowmeter; (5) convergent-divergent nozzle; (6) pressure sensors; (7) evaluating and recording equipment; (8) computer; (9) light; (10) high speed camera; (11) thermometer.

The ball valves were included in the circuit to control flow. In the case of a water line, the flow was controlled by a frequency converter located on the pump. The circuit was composed of DN20 plastic pipes. In the case of an oil line, the flow was controlled by a control hydrogenerator with a tilting plate and the circuit was composed of a DN20 steel pipe. It was possible to heat the oil on this circuit.

\section{Mathematical Model}

Flow is defined as multiphase flow (water-air-vapor, oil-air), so the multiphase mixture model was used. The model can solve homogeneous multiphase flow, where the individual phases move at different velocities. The mixture model consisted of the continuity equation for the mixture [18]:

$$
\frac{\partial \rho_{m}}{\partial t}+\nabla \cdot\left(\rho_{m} \vec{v}_{m}\right)=0\left(\mathrm{~kg} \cdot \mathrm{s}^{-1} \cdot \mathrm{m}^{-3}\right)
$$

where $\rho_{m}\left(\mathrm{~kg} \cdot \mathrm{m}^{-3}\right)$ is je mixture density, $\overrightarrow{v_{m}}\left(\mathrm{~m} \cdot \mathrm{s}^{-1}\right)$ is mass averaged velocity. After substituting:

$$
\begin{gathered}
\rho_{m}=\sum_{k=1}^{n}\left(\alpha_{k} \rho_{k}\right)\left(\mathrm{kg} \cdot \mathrm{m}^{-3}\right) \\
\overrightarrow{v_{m}}=\frac{\sum_{k=1}^{n}\left(\alpha_{k} \rho_{k} \vec{v}_{k}\right)}{\rho_{m}}\left(\mathrm{~m} \cdot \mathrm{s}^{-1}\right)
\end{gathered}
$$

$\alpha_{k}$ (1) is the volume fraction of phase $k, n=3$ ( 1 is liquid, 2 is air and 3 is vapor). The index $m$ signifies the mixture.

The momentum equation for the mixture is [18]:

$$
\frac{\partial}{\partial t}\left(\rho_{m} \vec{v}_{m}\right)+\nabla \cdot\left(\rho_{m} \vec{v}_{m} \vec{v}_{m}\right)=-\nabla p+\nabla \cdot\left[\mu_{m}\left(\nabla \vec{v}_{m}+\nabla \vec{v}_{m}^{T}\right)\right]+\rho_{m} \vec{g}+\vec{F}-\nabla \cdot\left(\sum_{k=1}^{n}\left(\alpha_{k} \rho_{k} \vec{v}_{d r, k} \vec{v}_{d r, k}\right)\right)
$$


where $n$ is the number of phases, $\vec{F}$ is a body force, $\vec{v}_{d r, k}=\vec{v}_{k}-\vec{v}_{m}$ is the drift velocity for the secondary phase $k, \mu_{m}(\mathrm{~Pa} \cdot \mathrm{s})$ is the viscosity of the mixture:

$$
\mu_{m}=\sum_{k=1}^{n}\left(\alpha_{k} \mu_{k}\right)(\mathrm{Pa} \cdot \mathrm{s})
$$

The gas density follows the equation of state with constant temperature, the liquid density is assumed to be incompressible. Therefore, the process is assumed to be isothermal.

Cavitation is characterized by a phase change between liquid and vapor, the equation for the volume fraction of vapor is defined as follows [18]:

$$
\frac{\partial}{\partial t}\left(\alpha_{\text {vap }} \rho_{\text {vap }}\right)+\nabla \cdot\left(\alpha_{\text {vap }} \rho_{\text {vap }} \vec{v}_{m}\right)=-\nabla \cdot\left(\alpha_{\text {vap }} \rho_{\text {vap }} \vec{v}_{d r, v a p}\right)+\sum_{q=1}^{n}\left(\dot{m}_{l \text { vap }}-\dot{m}_{\text {vap } l}\right)\left(\mathrm{kg} \cdot \mathrm{s}^{-1} \cdot \mathrm{m}^{-3}\right)
$$

where the indexes indicate the individual phases: vap — vapor, $l$-liquid, air —air.

The Schnerr and Sauer cavitation model [18] used is compatible with this mixture model. When entering the model, it is assumed that the mixture consists of a liquid and a vapor phase. The equation for the volume fraction of vapor has the form:

$$
\frac{\partial}{\partial t}\left(\alpha_{\text {vap }} \rho_{\text {vap }}\right)+\nabla \cdot\left(\alpha_{\text {vap }} \rho_{\text {vap }} \vec{v}_{m}\right)=R\left(\mathrm{~kg} \cdot \mathrm{s}^{-1} \cdot \mathrm{m}^{-3}\right)
$$

where $\alpha_{\text {vap }}(1)$ is the vapor volume fraction, $\rho_{\text {vap }}\left(\mathrm{kg} \cdot \mathrm{m}^{-3}\right)$ is the vapor density, $\overrightarrow{v_{m}}\left(\mathrm{~m} \cdot \mathrm{s}^{-1}\right)$ is the mixture velocity and $R\left(\mathrm{~kg} \cdot \mathrm{s}^{-1} \cdot \mathrm{m}^{-3}\right)$ is the mass transfer rate:

$$
R=\frac{\rho_{\text {vap }} \rho_{l}}{\rho_{m}} \alpha_{\text {vap }} \alpha_{l} \frac{3}{\Re_{B}} \sqrt{\frac{2}{3} \frac{p_{\text {vap }}-p}{\rho_{l}}}\left(\mathrm{~kg} \cdot \mathrm{s}^{-1} \cdot \mathrm{m}^{-3}\right)
$$

where $\rho_{l}\left(\mathrm{~kg} \cdot \mathrm{m}^{-3}\right)$ is liquid density, $\alpha_{l}(1)$ is the liquid volume fraction, $p_{v a p}(\mathrm{~Pa})$ is saturation vapor pressure and $\Re_{B}(\mathrm{~m})$ is the bubble radius:

$$
\Re_{B}=\left(\frac{\alpha_{\text {vap }}}{\alpha_{l}} \frac{3}{4 \pi} \frac{1}{n}\right)^{\frac{1}{3}}(\mathrm{~m})
$$

where $n$ is bubble number density. The Schnerr and Sauer models use vapor to connect a volume fraction of vapor to the number of bubbles per volume of liquid:

$$
\alpha_{\text {vap }}=\frac{n_{b} \frac{4}{3} \pi \Re_{B}^{3}}{1+n_{b} \frac{4}{3} \pi \Re_{B}^{3}}(-)
$$

The cavitation model of Schnerr and Sauer is based on the Rayleigh-Plesset equation [13]. It describes the growth of one vapor bubble in a liquid. Equation (13) describes the mass transfer between the liquid and vapor phase in cavitation:

$$
\Re_{b} \frac{D^{2} \Re_{b}}{D t^{2}}+\frac{3}{2}\left(\frac{D \Re_{b}}{D t}\right)^{2}=\left(\frac{p_{b}-p}{\rho_{l}}\right)-\frac{4 v_{l}}{\Re_{b}} \Re_{b}-\frac{2 \sigma}{\rho_{l} \Re_{b}}\left(\mathrm{~m}^{2} \cdot \mathrm{s}^{-2}\right)
$$

where $\Re_{b}(\mathrm{~m})$ is the bubble radius, $\sigma$ (Pa $\cdot \mathrm{m}^{-1}$ ) is the liquid surface tension coefficient, $v_{l}\left(\mathrm{~m}^{2} \cdot \mathrm{s}^{-1}\right)$ is the liquid kinematic viscosity, $p(\mathrm{~Pa})$ is local far-field pressure. Neglecting the second-order terms and the surface tension force, Equation (13) is simplified to:

$$
\frac{D \Re_{b}}{D t}=\sqrt{\frac{2}{3} \frac{p_{b}-p}{\rho_{l}}}\left(\mathrm{~m} \cdot \mathrm{s}^{-1}\right)
$$

Due to the Reynolds number determined from the experiment, it is a flow transient between the laminar and turbulent modes. Therefore, the problem will be solved by 
a time-averaged turbulent model suitable for low Reynolds numbers. The goal of the Reynolds-Averaged Navier-Stokes (RANS) approach is to simulate a time-averaged flow field. A large number of RANS models are based on the Boussinesque hypothesis. This assumes that the stress tensor defined by Newton's relation can be used for a turbulent stress tensor. The molecular viscosity is then replaced by the so-called turbulent viscosity. The continuity Equation (3), the equation of motion (6) and others in the mixture model (8) will be defined for time-averaged quantities.

The two-equation model $k-\omega$ adds two differential equations $[18,19]$. The velocity scale of turbulence is specified by means of the turbulent kinetic energy $k\left(\mathrm{~m}^{-2} \cdot \mathrm{s}^{-2}\right)$. The longitudinal scale of turbulence is solved by means of the vorticity $\omega\left(\mathrm{s}^{-1}\right)$ :

$$
\begin{aligned}
& \frac{\partial k}{\partial t}+\nabla \cdot\left(\vec{v}_{m} k\right)=\nabla \cdot\left(\Gamma_{k} \nabla k\right)\left(\mathrm{m}^{2} \cdot \mathrm{s}^{-3}\right) \\
& \frac{\partial \omega}{\partial t}+\nabla \cdot\left(\vec{v}_{m} \omega\right)=\nabla \cdot\left(\Gamma_{\omega} \nabla \omega\right)\left(\mathrm{s}^{-2}\right)
\end{aligned}
$$

In these equations $\Gamma_{k}\left(\mathrm{~m}^{2} \cdot \mathrm{s}^{-1}\right)$ and $\Gamma_{\omega}\left(\mathrm{m}^{2} \cdot \mathrm{s}^{-1}\right)$ are the effective diffusivity of $k\left(\mathrm{~m}^{-2} \cdot \mathrm{s}^{-2}\right)$ and $\omega\left(\mathrm{s}^{-1}\right)$, respectively.

The Shear Stress Transport SST k- $\omega$ model used in solution [4,18-24] is a modification of the basic k- $\omega$ model. It has a modified differential equation for vorticity. The model is suitable where it is necessary to precisely determine the tear-off point and the size of the closing area.

The SST model takes into account the transfer of the shear stress of turbulence in the definition of turbulent viscosity:

$$
\mu_{t}=\frac{\rho k}{\omega} \frac{1}{\max \left[\frac{1}{\alpha^{*}}, \frac{S F_{2}}{a_{1} \omega}\right]}(\mathrm{Pa} \cdot \mathrm{s})
$$

where $S\left(\mathrm{~Pa} \cdot \mathrm{s}^{-1}\right)$. is the magnitude of the strain rate, $\alpha^{*}(1)$ is defined in Equation (19) and $F_{2}(1)$ is given by:

$$
F_{2}=\tanh \left(\max \left[2 \frac{\sqrt{k}}{0.09 \omega y}, \frac{500 \mu}{\rho y^{2} \omega}\right]\right)^{2}(-)
$$

where $y(\mathrm{~m})$. is the distance to the next area.

$$
\alpha^{*}=\alpha_{\infty}^{*}\left(\frac{\frac{0.072}{3}+\frac{\rho k}{6 \mu \omega}}{1+\frac{\rho k}{6 \mu \omega}}\right)(-)
$$

Cavitation is characterized by time changes of solved hydraulic quantities with high frequency. To achieve convergence, it is necessary to solve the problem as time-dependent with a small time step and averaged values used for evaluation.

The simulation was performed using Ansys Fluent 2020 R2 software. From the authors' experience, it was decided to model the geometry as 2D axially symmetric (see Figure 4). However, it was necessary to create a very fine mesh. Several variants of mesh with refinement at the walls were created. Grids were tested using grid convergence analysis. Due to the different distances from the inlet and outlet, there was a difference in the number of cells- the mesh created for the water flow had 242,450 cells, and the mesh created for the oil flow had 166,090 cells.

At the inlet, the various flow rate values for individual phases were set. The measured volume flow for water ranged from $\mathrm{Q}=1.74 \times 10^{-4} \mathrm{~m}^{3} \cdot \mathrm{s}^{-1}$ to $\mathrm{Q}=7.23 \times 10^{-4} \mathrm{~m}^{3} \cdot \mathrm{s}^{-1}$ and for oil from $\mathrm{Q}=1.70 \times 10^{-4} \mathrm{~m}^{3} \cdot \mathrm{s}^{-1}$ to $\mathrm{Q}=5.86 \times 10^{-4} \mathrm{~m}^{3} \cdot \mathrm{s}^{-1}$. The outlet boundary condition was given by setting the measured pressure values at the outlet. For water, the absolute pressure range was from $93,500 \mathrm{~Pa}$ to $99,000 \mathrm{~Pa}$. For oil, this range was from 91,300 Pa to $104,100 \mathrm{~Pa}$. A hydraulic diameter of $0.02 \mathrm{~m}$ and a turbulence intensity value of 
$1 \%$ were set for the inlet and outlet. In the case of cavitation, the problems were solved as time-dependent.

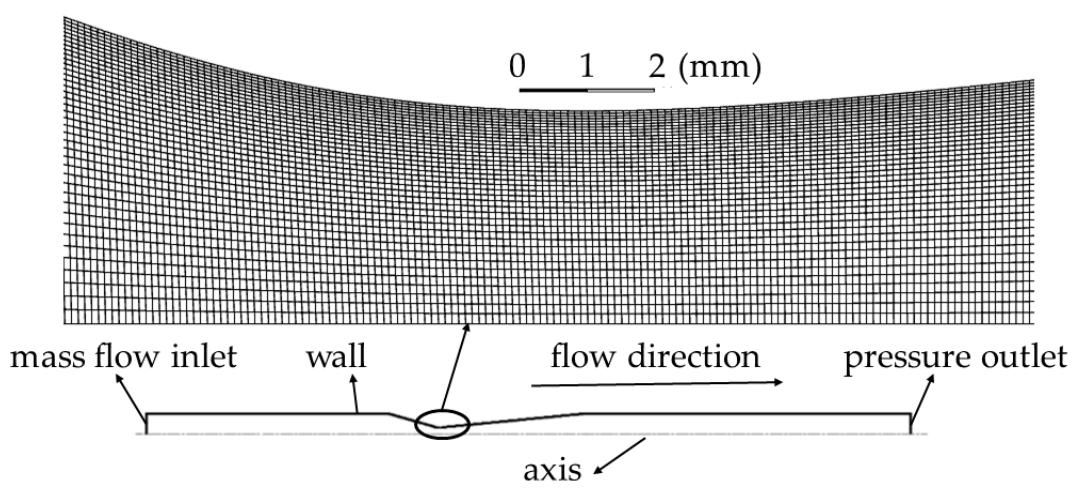

Figure 4. Boundary conditions and mesh of the modeled area of the convergent-divergent nozzle.

\section{Results of Measurements and Modeling}

\subsection{Measurement Results}

Figure 5 presents the measured values of inlet and outlet pressure vs. volume flow rate. With an increasing flow rate, the pressure at the inlet and outlet increased, which corresponds to Weissbach's theory of fluid mechanics. The pressure values for water agree with the Weissbach theory up to a volume flow value of $4.51 \times 10^{-4} \mathrm{~m}^{3} \cdot \mathrm{s}^{-1}$. For higher flow values, the inlet pressure values $p_{1}(\mathrm{~Pa})$ had a steeper increase due to cavitation. The hydraulic resistance of the element increased during flow with cavitation. In the case of water, a break in characteristics corresponding to the cavitation formation is evident. In the case of oil, the pressures for three variants of temperature were evaluated. No cavitation occurred at $25^{\circ} \mathrm{C}$. At $40^{\circ} \mathrm{C}$ and $50{ }^{\circ} \mathrm{C}$, cavitation occurred at higher flow rates. The minimum flow value for cavitation for $40{ }^{\circ} \mathrm{C}$ is greater than $5.5 \times 10^{-4} \mathrm{~m}^{3} \cdot \mathrm{s}^{-1}$ and the minimum flow value for $50^{\circ} \mathrm{C}$ is greater than $5.02 \times 10^{-4} \mathrm{~m}^{3} \cdot \mathrm{s}^{-1}$. The inlet pressure increased but less than according to Weissbach's theory. There is no apparent break in oil characteristics with cavitation.

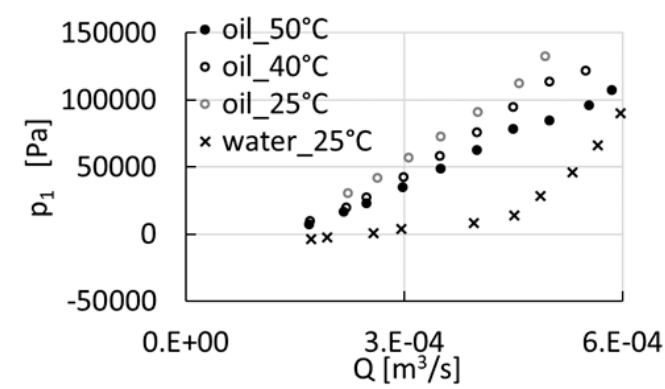

(a)

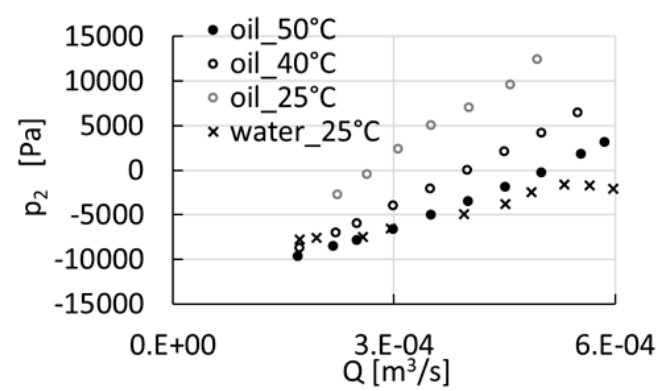

(b)

Figure 5. (a) Dependence of relative inlet pressure $p_{1}(\mathrm{~Pa})$ vs. volume flow rate $Q\left(\mathrm{~m}^{3} \cdot \mathrm{s}^{-1}\right)$; (b) Dependence of relative outlet pressure $p_{2}(\mathrm{~Pa}) \mathrm{vs}$. volume flow rate $Q\left(\mathrm{~m}^{3} \cdot \mathrm{s}^{-1}\right)$.

The loss coefficient $\xi$ (1) was determined using Bernoulli's equation:

$$
\Delta p=\xi \rho \frac{8}{\pi^{2} D^{4}} Q^{2} \rightarrow \xi=\Delta p \frac{\pi^{2} D^{4}}{8 \rho Q^{2}}(\mathrm{~Pa})
$$

and discharge coefficient $\mu(1)$ :

$$
\mu=\sqrt{\frac{1}{1-\xi}}(-)
$$


The flow coefficient expresses the loss caused by the flow through a narrowed crosssection (nozzles, orifices, valve). It is commonly used in hydraulics. The type of flow was specified by the Reynolds number using parameters of inlet cross-section and viscosity:

$$
R e_{\text {inlet }}=\frac{\rho v_{\text {inlet }} D}{\eta}(-)
$$

The critical Reynolds number was considered 2320. The water flow was turbulent in the range of measurement, see Figure 6a. The oil flow was laminar, but with increasing temperature and decreasing oil viscosity, turbulent flow could be achieved. The laminar flow was also at the narrowest point of the nozzle during oil flow. From the graphs, it is evident that the loss coefficient changes significantly with cavitation.

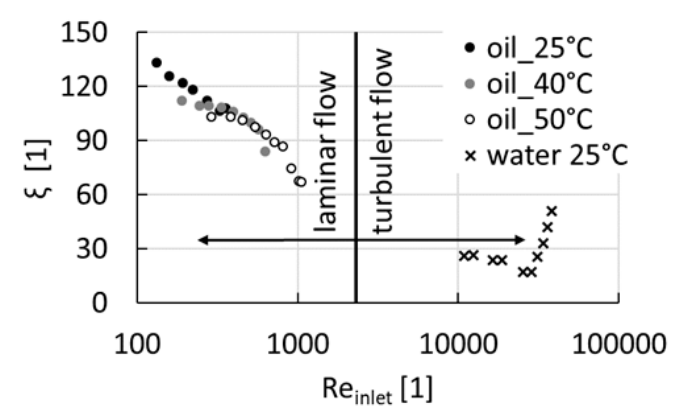

(a)

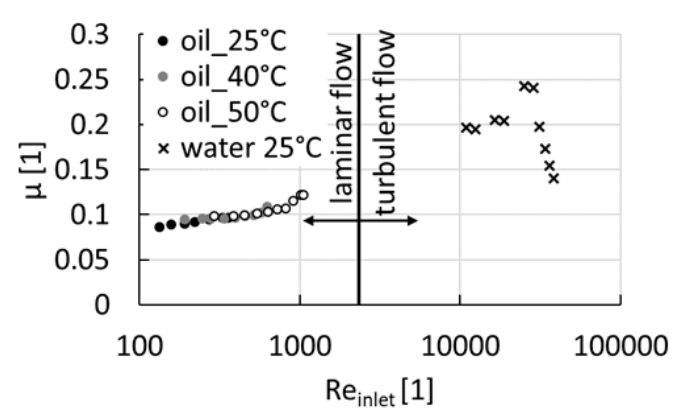

(b)

Figure 6. (a) Dependence of loss coefficient $\xi$ (1) vs. Reynolds number at the inlet $R e_{\text {inlet }}(1)$; (b) Dependence of discharge coefficient $\mu$ (1) vs. Reynolds number at the inlet $R e_{\text {inlet }}$ (1).

In Figure 6a, when oil flows in the laminar region, the loss coefficient is continuously decreasing except for flows where cavitation occurs. The loss coefficient for water varies significantly. For flows without cavitation, a decrease in the loss coefficient is noticeable, while the loss coefficient increases sharply with the increasing flow in the cavitation area. For flow $4.51 \times 10^{-4} \mathrm{~m}^{3} \cdot \mathrm{s}^{-1}$. the loss coefficient at the interface between the cavitation and cavitation modes is minimal and has a value of 17.02 .

Figure $6 \mathrm{~b}$ shows the inverse course of the flow coefficient with respect to the loss coefficient. For flow $4.51 \times 10^{-4} \mathrm{~m}^{3} \cdot \mathrm{s}^{-1}$. the flow coefficient at the interface between cavitation and without cavitation mode is maximal and has a value of 0.25 .

The potential for cavitation formation is given by the cavitation number and it was used to analyze the results. The cavitation number is defined as the ratio of the pressure drop at the nozzle inlet to the kinetic energy [19]:

$$
\sigma=\frac{2\left(p_{\text {in }}-p_{\text {vap }}\right)}{\rho v_{\text {nozzle }}^{2}}(-)
$$

The relationship between both dimensionless parameters (cavitation number, Reynolds number in the nozzle) is displayed in Figure 7. The critical cavitation number defined from the measurement (by observing the cavitation formation) was the same for both liquids and took the values $\sigma=0.747$ (1) for the given nozzle geometry. It is evident that the formation of cavitation does not depend on the type of fluid, but on the hydraulic parameters, i.e., pressure and flow rate. There are marked variants, which will be numerically analyzed. 

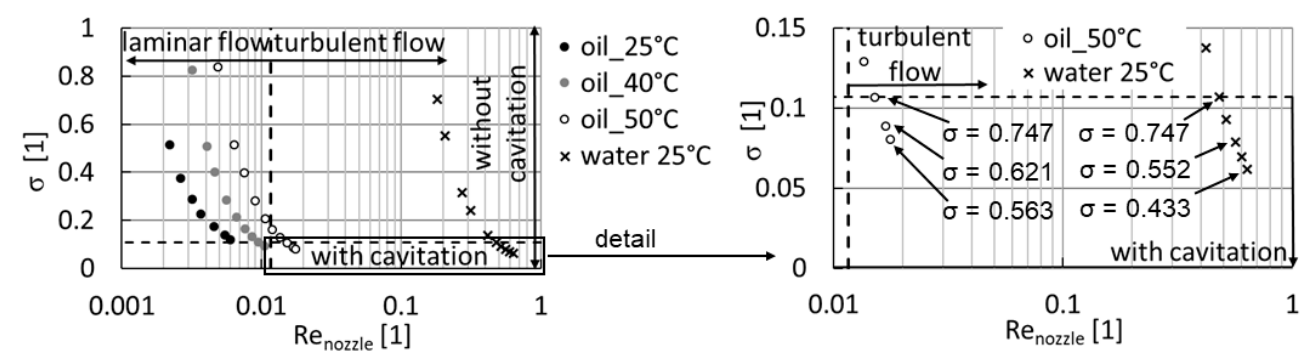

Figure 7. Dependence of cavitation number $\sigma(1)$ vs. Reynolds number in the narrowest cross-section $R e_{\text {nozzle }}(1)$; detail of the cavitation area is to the right.

\subsection{Results of Modeling}

The single-phase model can be used to estimate the type of flow, simple task entry and short computational time. In the case of water cavitation, a two-phase model (water-vapor) is commonly used. Due to the inaccuracies of the results, the model was extended to a three-phase model (water-vapor-air). The accuracy of the calculation depends on the correct determination of the amount of air in the water depending on the temperature and pressure.

There were three simulating variants of the water flow through the nozzle:

(a) single-phase flow: water flow;

(b) two-phase flow: water and vapor flow;

(c) three-phase flow: water, vapor and air flow.

Due to the input boundary conditions, absolute pressure $p_{1}$ was simulated and subsequently verified with the measurement. Figure 8 presents the average values of the absolute inlet pressure depending on the volume flow rate when water and oil flowed through the nozzle. Figure 8a shows the differences between the simulated and measured inlet pressure in the water flow as a function of the number of phases. In the case of flow without cavitation, the differences of the individual variants were slight. In the case of flow without cavitation, the deviations of the measured pressure $p_{1}(\mathrm{~Pa})$ from the simulated values $p_{1}(\mathrm{~Pa})$ for the single-phase, two-phase and three-phase models were minimal. In the case of flow with cavitation, the one-phase and two-phase models differed significantly from the experiment and the three-phase model shows minimal deviations.

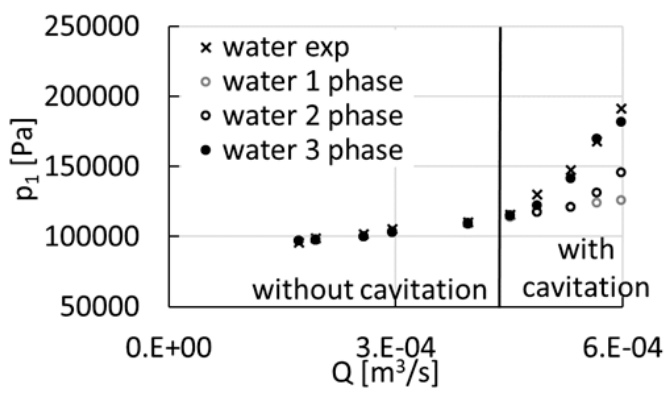

(a)

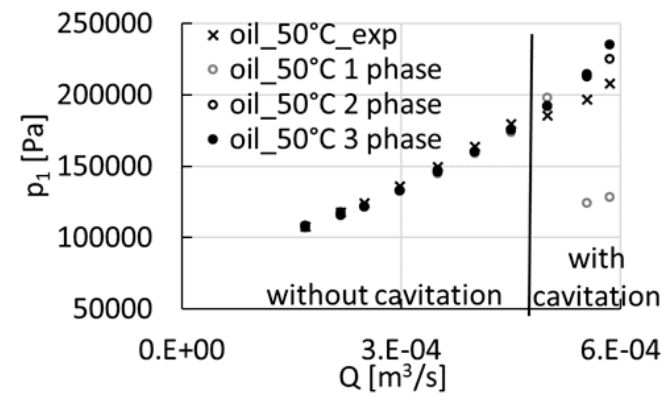

(b)

Figure 8. (a) Dependence of inlet pressure $p_{1}(\mathrm{~Pa})$ vs. volume flow rate $Q\left(\mathrm{~m}^{3} \cdot \mathrm{s}^{-1}\right)$ for water; (b) Dependence of inlet pressure $p_{1}(\mathrm{~Pa})$ vs. volume flow rate $Q\left(\mathrm{~m}^{3} \cdot \mathrm{s}^{-1}\right)$ for Oil.

Air cavitation occurs mainly in oil and vapor cavitation was not achieved at the given pressure and temperature (see Figure 2). For comparison, the same variants were simulated.

(a) single-phase flow: oil flow;

(b) two-phase flow: oil and air flow;

(c) three-phase flow: oil, vapor and air flow. 
Figure $8 \mathrm{~b}$ again shows no differences of individual variants in modeling flow without cavitation. When modeling oil flow with cavitation, a significant difference at inlet pressure is evident for the one-phase variant. The deviations between the two-phase (oil, air) and three-phase model (oil, air, vapor) are not so important, because the vapor cavitation was not achieved. At the narrowest point, the lowest modeled pressure was $8500 \mathrm{~Pa}$.

Figure 9 evaluates the deviations of the simulated values of individual variants and the measured values depending on the cavitation number. Figure 9a presents a result for water. The pressure deviations without cavitation were very small, they had values up to $2 \%$. However, when modeling flow with cavitation, it is necessary to define vapor and air components in the liquid. In the two-phase model (water, vapor) the deviations were smaller, but the model was still not accurate enough. With the extended definition of the concentration of non-condensable gas in the water, the pressure deviations at the inlet during the flow with cavitation were up to $5 \%$.

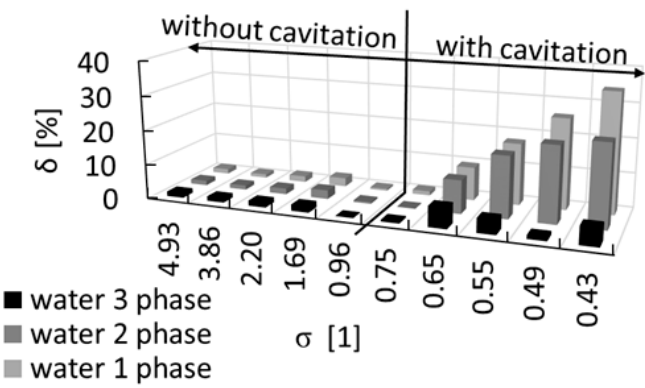

(a)

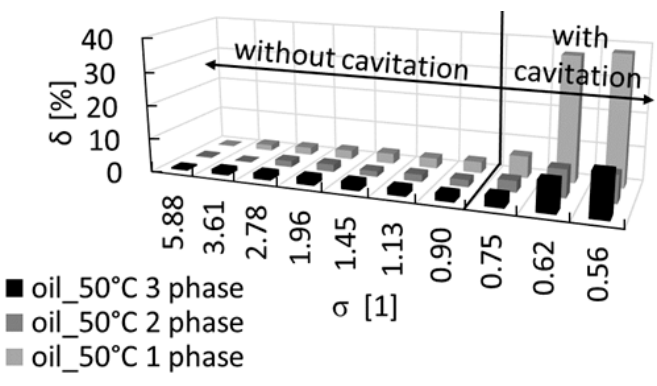

(b)

Figure 9. (a) Dependence of deviation measurement $\delta(\%)$ vs. cavitation number $\sigma(1)$ for water; (b) Dependence of deviation measurement $\delta(\%)$ vs. cavitation number $\sigma(1)$ for oil.

Figure $9 \mathrm{~b}$ shows that the oil deviations for oil were the smallest for the two-phase model (oil, air), and had values up to $2.5 \%$. The three-phase model (oil, vapor, air) differs very little from the two-phase model due to a more complex mathematical model and rounding errors. When calculating the three-phase model, the computational time was longer, and the calculation was less stable.

The statistically average values of the pressures on the wall in the narrowed part of the nozzle are presented in detail in Figure 10. A three-phase model (water, vapor, air) is simulated for water, and a two-phase model for oil (oil, air). For water and oil, a variant of the initial cavitation $\sigma=0.747$ (1) is plotted, followed by two variants of the developed cavitation. The low-pressure range for the oil is shorter and smoother. The range of minimum pressure in water is caused by the formation of vapor and the flow of air as a compressible medium. The size of the cavitation cloud in water flow is significantly longer than in oil. This is affected by the flow of air in the oil.
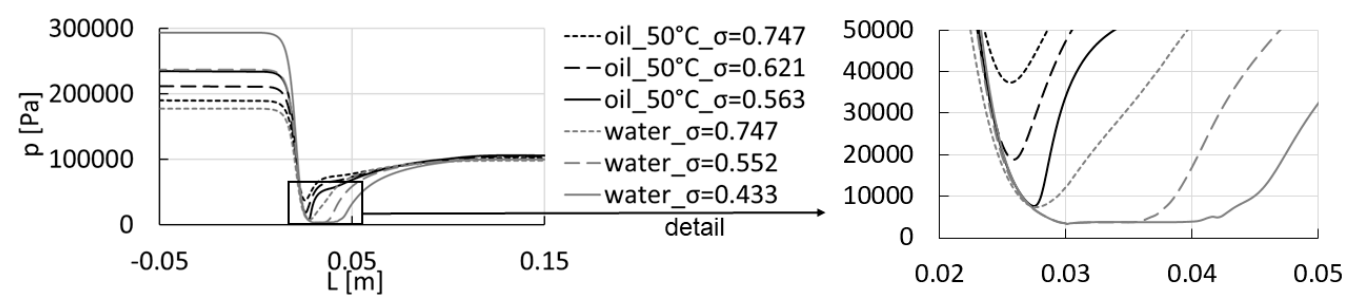

Figure 10. Dependence of pressure on the wall $p$ vs. length $L$; the detail is to the right.

Volume flows are given for these cavitation numbers:

(a) water comparison:

$\sigma=0.747$ (initial cavitation, $\mathrm{Q}=4.51 \times 10^{-4} \mathrm{~m}^{3} \cdot \mathrm{s}^{-1}$ )

$\sigma=0.552$ (developed cavitation, $\mathrm{Q}=5.53 \times 10^{-4} \mathrm{~m}^{3} \cdot \mathrm{s}^{-1}$ ),

$\sigma=0.433$ (fully developed cavitation, $\mathrm{Q}=5.98 \times 10^{-4} \mathrm{~m}^{3} \cdot \mathrm{s}^{-1}$ ) 
(b) oil comparison:

$$
\begin{aligned}
& \sigma=0.747 \text { (initial of cavitation, } \mathrm{Q}=4.51 \times 10^{-4} \mathrm{~m}^{3} \cdot \mathrm{s}^{-1}, \mathrm{~T}=50{ }^{\circ} \mathrm{C} \text { ) } \\
& \sigma=0.621 \text { (developed cavitation, } \mathrm{Q}=5.54 \times 10^{-4} \mathrm{~m}^{3} \cdot \mathrm{s}^{-1}, \mathrm{~T}=50{ }^{\circ} \mathrm{C} \text { ) } \\
& \sigma=0.563 \text { (fully developed cavitation, } \mathrm{Q}=5.86 \times 10^{-4} \mathrm{~m}^{3} \cdot \mathrm{s}^{-1}, \mathrm{~T}=50^{\circ} \mathrm{C} \text { ), }
\end{aligned}
$$

Due to the pressure distribution on the wall, see Figure 10, it is possible to justify the distribution of the volume fraction of gas evaluated on the nozzle wall during the water flow and the oil flow. The volume fraction of gas in water is significantly larger than in oil.

In Figure 11, the average gas volume fraction in the constricted part of the nozzle is compared. For water, it is the sum of the average values of the vapor and air volume fractions (three-phase model) and for oil, only the average value of the air volume fraction (two-phase model).

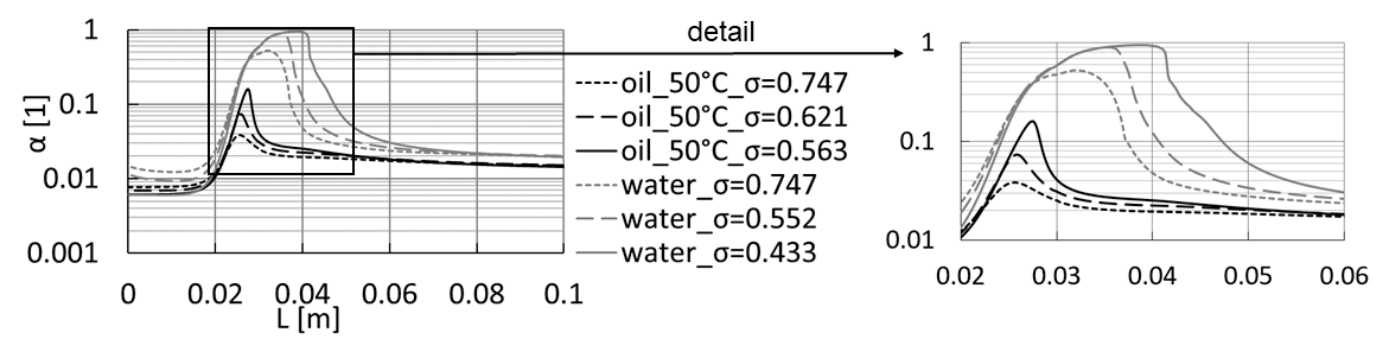

Figure 11. Dependence of volume fraction of gas $\alpha(1)$ vs. length $L(\mathrm{~m})$; the detail is to the right.

Figure 12 gives the photographs of instantaneous gas clouds in the measurements. Simulated results are time-averaged. These experimental results document the distribution of gases in the cavitation region in accordance with Figures 10 and 11. The modeled and experimentally determined areas of cavitation roughly agree.
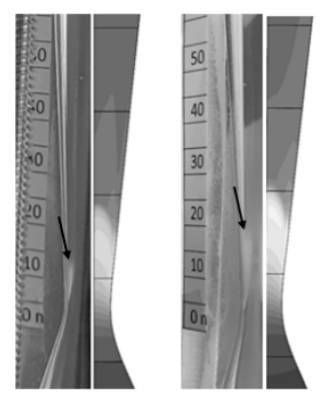

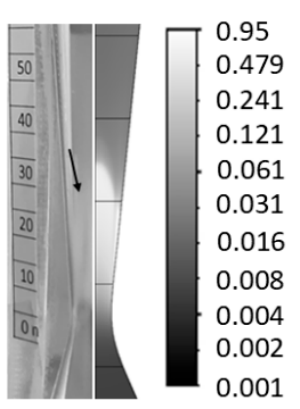

(a)
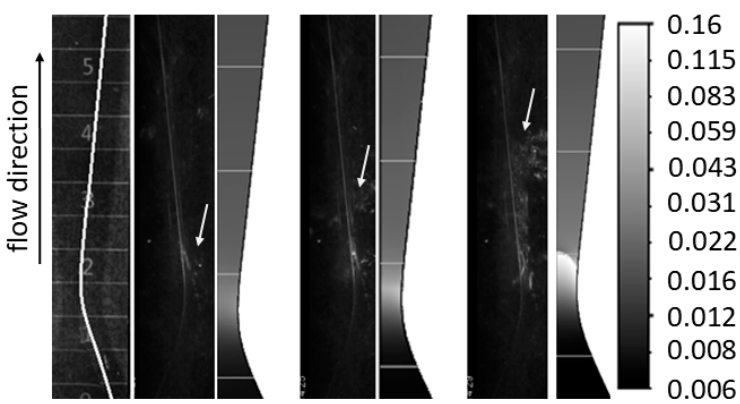

(b)

Figure 12. Comparison of cavitation cloud size, experiment on the left, numerical model on the right: (a) water; (b) oil.

Figure 13a shows the cavitation cloud lengths for the evaluated variants (water and oil). The modeled cavitation cloud is overestimated for water. For oil, the modeled cavitation cloud is underestimated, see Figure $13 \mathrm{~b}$. 


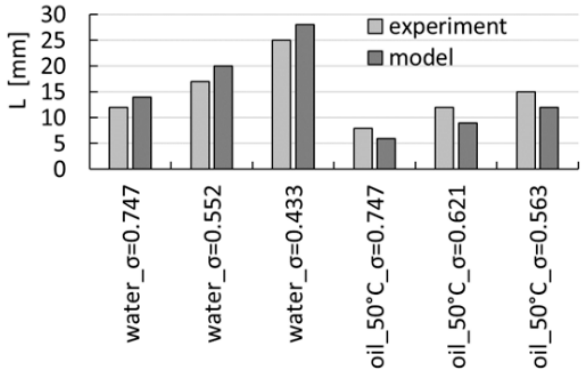

(a)

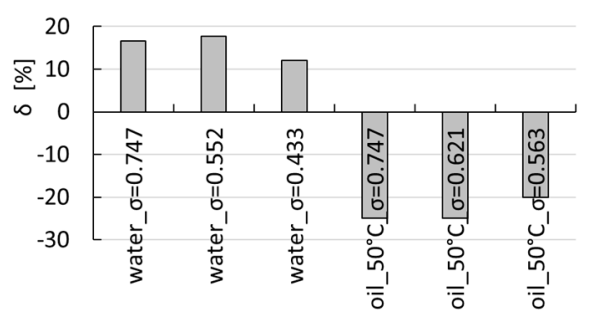

(b)

Figure 13. (a) Dependence of length of cavitation cloud $L$ from experiment and simulation for water and oil and various cavitation numbers. (b) Dependence of deviation $\delta(\%)$ of cavitation cloud length from experiment and simulation for water and oil and various cavitation numbers.

\section{Conclusions}

This work is devoted to the experimental and mathematical investigation of cavitation phenomena in a convergent-divergent nozzle of circular cross-section. The liquid examined was water and then oil. Research into cavitation in water has long been carried out both experimentally and mathematically, as cavitation is very often found in hydraulic machines. Cavitation in oil is studied very little, although the consequences in oil and water hydraulics are the same. The same research methods were applied to the oil. To investigate cavitation, an experimental device was designed so that it was possible to monitor the size of the cavitation cloud depending on the type of flowing medium (water and oil), its temperature and the size of the cavitation bubbles. During cavitation, the dynamic behavior of the cavitation cloud was observed. The experimental results served as boundary conditions for mathematical models of cavitation and their verification.

Evaluation of the experimental results:

- The basic hydraulic quantity, i.e., the volume flow, was chosen equally for water and oil for easier comparison of results;

- The formation of cavitation depends on the physical properties of the fluids (density, dynamic or kinematic viscosity), which can be a function of temperature, especially for oils;

- Static characteristics did not show a smooth course according to Weissbach's theory. In the cavitation flow of water there was a sharp increase in the pressure drop, in the cavitation flow of oil there was a decrease in the pressure drop;

- The loss coefficient at the interface between the cavitation and non-cavitation areas reached a minimum for water and a maximum for oil, with the flow coefficient contrary to this;

- The cavitation number generally depends on the static inlet pressure, the dynamic pressure in the nozzle and the saturated vapor pressure, i.e., the flowing liquid;

- $\quad$ The critical cavitation number in the same nozzle was the same for water and oil 0.747 and did not depend on the physical properties of the liquid;

- The Reynolds number was evaluated to estimate the type of flow. The water flow was turbulent and the oil flow was laminar. Liquids were considered incompressible, the gases compressible;

- The flow of water and oil showed a slightly dynamic behavior, therefore, the measured basic hydraulic quantities, i.e., inlet and outlet pressure and flow were averaged. Significant dynamics can be observed on the cavitation cloud. The size of the cavitation cloud depended on the type of liquid;

- The cavitation bubbles in the water were significantly smaller compared to the bubbles in the oil.

During cavitation, each flowing liquid contained gases. When the pressure dropped below the saturated vapor pressure, it contained vapor. In addition, all liquids contained air, which significantly affected the flow, especially at low pressures. Therefore, a flowing liquid 
was defined as a multiphase liquid (water, vapor, air). In water, cavitation is emphasized in the literature due to the release of vapor, in oil by the release of air. Three variants of multiphase liquids (liquid, liquid-vapor, liquid-air, liquid-vapor-air) were created and verified with experiments. The inlet pressure was compared.

Mathematical models were solved in ANSYS Fluent software by the finite volume method. A laminar model (DNS) was used for laminar oil flow. An SST K-om turbulence model was used for the turbulent flow of water and partially oil.

Evaluation of simulation and verification results with the experiment:

- It is sufficient to solve the flow of water and oil in non-cavitation mode with a singlephase liquid;

- Water flow with cavitation was solved by water, water-vapor, water-vapor-air models. The three-phase model differed minimally in the average values of pressure and the size of the cavitation cloud. The single-phase and two-phase models showed large deviations from the experiment;

- The cavitation flow of the oil solved by the single-phase model did not show pressure values in the nozzle area under the pressure of saturated oil vapors. Therefore, a two-phase oil-air model and then a three-phase model was tested. Both multiphase models showed good pressure agreement with the experiment. The results of the simulation with a single-phase model differed from the experiment.

In conclusion, the extended three-phase mathematical model of cavitation is suitable for the simulation of flow in common hydraulic fluids (water, oil). The simplified twophase oil-air model is applicable in the case of cavitation flow when the pressure in the liquid does not reach the pressure of saturated vapors. This can be partially estimated by solving a single-phase model. The accuracy of the mathematical model depends on the accuracy of the boundary conditions, especially on the air content in the liquid. In oil, this quantity is difficult to determine.

In the future, the cavitation model of oil flow will be tested in a physical experiment with larger flow rates to achieve a saturated oil vapor pressure of the order of $\mathrm{Pa}$ and in more complex geometries such as valves.

In three-dimensional space, other turbulence models can be used, especially for the calculation of cavitation cloud dynamics, i.e., LES models and combinations of LES and RANS. Cavitation is manifested primarily by noise and vibration. These quantities are easily measurable. Spectral analysis is, therefore, another method of verifying mathematical models of turbulence experiments, it was used in cavitation in water in [25]. Spectral analysis for cavitation in oil will be used in the future. The advantage is the possibility of identifying cavitation in hydraulic devices, where the visualization method cannot be used.

Author Contributions: Conceptualization, M.K. and J.J.; methodology, M.B.; software, M.B., M.K. and J.J; validation M.K. and J.J; formal analysis, J.J.; resources, J.J.; data curation, M.K. and J.J.; writing — original draft preparation, M.K. and J.J.; visualization, J.J. All authors have read and agreed to the published version of the manuscript.

Funding: "This work was supported by the European Regional Development Fund in the Research Centre of Advanced Mechatronic Systems project, project number CZ.02.1.01/0.0/0.0/16_019/0000867 within the Operational Programme Research, Development and Education" and "The work presented in this paper was supported by a grant SGS" Control of Fluid Systems and their Parameters Measurement. "SP2021/85".

Institutional Review Board Statement: Not applicable.

Informed Consent Statement: Not applicable.

Data Availability Statement: Not applicable.

Conflicts of Interest: The authors declare no conflict of interest. 


\section{References}

1. Zhang, F.; Chen, J.; Su, C.; Ma, C. Energy Consumption and Economic Analyses of a Supercritical Water Oxidation System with Oxygen Recovery. Processes 2018, 6, 224. [CrossRef]

2. Panda, D.; Saharan, V.K.; Manickam, S. Controlled Hydrodynamic Cavitation: A Review of Recent Advances and Perspectives for Greener Processing. Processes 2020, 8, 220. [CrossRef]

3. Li, M.; Bussonnière, A.; Bronson, M.; Xu, Z.; Liu, Q. Study of Venturi tube geometry on the hydrodynamic cavitation for the generation of microbubbles. Miner. Eng. 2019, 132, 268-274. [CrossRef]

4. Li, H.; Li, H.; Huang, X.; Han, Q.; Yuan, Y.; Qi, B. Numerical and Experimental Study on the Internal Flow of the Venturi Injector. Processes 2020, 8, 64. [CrossRef]

5. Bojko, M.; Kozubková, M.; Jablonská, J. Cavitation Flow of Oil and Water Through the Nozzle. MATEC Web Conf. 2020, 328, 03012. [CrossRef]

6. Li, Z.; Li, Y.; Cao, H.; Hao, M.; Liu, F.; Meng, D. Investigation of cavitation evolution and hydrodynamic performances of oil film seal with spiral groove. Tribol. Int. 2021, 157, 106915. [CrossRef]

7. Poddar, S.; Tandon, N. Detection of journal bearing vapour cavitation using vibration and acoustic emission techniques with the aid of oil film photography. Tribol. Int. 2016, 103, 95-101. [CrossRef]

8. Dagilis, V.; Vaitkus, L. Analysis of lubricity and cavitation problem of oil and refrigerant mixture for hermetic compressors. Int. J. Refrig. 2017, 83, 99-107. [CrossRef]

9. Kolhe, N.S.; Gupta, A.R.; Rathod, V.K. Production and purification of biodiesel produced from used frying oil using hydrodynamic cavitation. Resour. Effic. Technol. 2017, 3, 198-203. [CrossRef]

10. Hao, Z.-R.; Gu, C.-W. Numerical modeling for gaseous cavitation of oil film and non-equilibrium dissolution effects in thrust bearings. Tribol. Int. 2014, 78, 14-26. [CrossRef]

11. Dvořák, L. Vlastnosti Tekutin [Online]. Ostrava: VŠB-TU Ostrava. 2010. Available online: https://www.fs.vsb.cz/338/cs/ studium/skripta/ (accessed on 22 December 2020).

12. Noskievič, J. Kavitace v Hydraulických Strojích; SNTL—Nakladatelství Technické Literatury: Praha, Czech Republic, 1989; 333p, ISBN 80-03-00206-0.

13. Schauer, P. Aplikovaná Fyzika: Fázové Přechody [Online]. Brno: Vysoké Učení Technické v Brně. 2006. Available online: https:/ / www.vut.cz/lide/pavel-schauer-1114/publikace (accessed on 21 April 2021).

14. Battlno, R.; Rettich, T.R.; Tominagab, T. The Solubility of Oxygen and Ozone in Liquids. J. Phys. Chem. Ref. Data 1983, 12, 163-178. [CrossRef]

15. Li, W.-G. Modeling Viscous Oil Cavitating Flow in a Centrifugal Pump. J. Fluids Eng. 2015, 138, 011303. [CrossRef]

16. Bureček, A.; Hružík, L.; Vašina, M. Determination of undissolved air content in oil by means of a compression method. Stroj. Vestn. J. Mech. Eng. 2015, 61, 7-8. [CrossRef]

17. Mikulčák, J. Matematické, Fyzikální a Chemické Tabulky; Prometheus: Praha, Czech Republic, 2003; ISBN 978-80-7196-264-9.

18. Help Fluent 2020 R2. Available online: https://ansyshelp.ansys.com/account/secured?returnurl=/Views/Secured/corp/v202 /en/flu_ug/flu_ug.html (accessed on 28 April 2021).

19. Menter, F.R.; Kuntz, M.; Langtry, R. Ten Years of Experience with the SST Turbulence Model. Turbul. Heat Mass Transf. 2003, 4, 625-632.

20. Shi, G.; Dan, Y.; Liu, X.; Shu, Z. Effect of the Inlet Gas Void Fraction on the Work Performance of the Multiphase Pump at Different Cavitation Stages. Processes 2021, 9, 1006. [CrossRef]

21. Wang, W.; Li, Y.; Osman, M.K.; Yuan, S.; Zhang, B.; Liu, J. Multi-Condition Optimization of Cavitation Performance on a Double-Suction Centrifugal Pump Based on ANN and NSGA-II. Processes 2020, 8, 1124. [CrossRef]

22. Menter, F.R. Two-equation eddy-viscosity turbulence models for engineering applications. AIAA J. 1994, 32, 1598-1605. [CrossRef]

23. Shi, H.; Li, M.; Nikrityuk, P.; Liu, Q. Experimental and numerical study of cavitation flows in venturi tubes: From CFD to an empirical model. Chem. Eng. Sci. 2019, 207, 672-687. [CrossRef]

24. Brennen, C.E. Cavitation and Bubble Dynamics; Cambridge University Press: New York, NY, USA, 2014.

25. Jablonská, J.; Kozubková, M.; Mahdal, M.; Marcalík, P.; Tůma, J.; Bojko, M.; Hruzík, L. Spectral analysis of gaseous cavitation in water through multiphase mathematical and acoustic methods. Phys. Fluids 2021, 33, 085128. [CrossRef] 